\title{
A (des) construção do ideal de virilidade e o homoerotismo: compreendendo a(s) masculinidade(s) no principado romano
}

Danieli Mennitti*

Resumo: Este artigo tem como objetivo realizar uma reflexão sobre o ideal de virilidade como princípio de conduta do cidadão romano, dentro de um discurso oficial, no período do principado, além de entender as o homoerotismo. A partir das representações epigramáticas de Marcial, analisadas a partir da perspectiva dos estudos de gênero, foi possível mostrar como, além de não existir um único modelo de masculinidade, esta, por sua vez, não é algo dado, mas sim construído social e culturalmente.

Palavras-chave: Virilidade; homoerotismo; cidadão.

Abstract: This article aims to develop a reflection on the ideal of manhood as a principle of behavior of the Roman citizen, within an official discourse, in the period of the Roman Principate and understand homoeroticism. From the representations of Martial's epigramms, analyzed from the perspective of gender studies, it was possible to show how there is no single model of masculinity, this, in turn, is not a given, but socially and culturally constructed .

Keywords: Manhood; homoroticism; citizen.

\section{Introdução}

Tem ocorrido um aumento no interesse pelas questões que envolvem o homem e as masculinidades na comunidade acadêmica e na sociedade de uma maneira genérica. Em muitas dessas discussões, é feita uma alusão a uma dita "crise da masculinidade", que, além de ser tributária do próprio decorrer do processo histórico em si, é calcada nos questionamentos proporcionados pelos movimentos gay e lésbico, pelos movimentos feministas, que por sua vez questionaram, entre outros assuntos, essa masculinidade hegemônica. Esses movimentos também geraram estudos que possibilitariam novos temas e abordagens para se pensar essa sociedade e a pesquisa histórica.

Tendo em vista que um historiador, deve sempre partir do seu presente, das indagações que faz e da problematização da sociedade de seu tempo, foram tecidas algumas reflexões que envolvem masculinidades, homens e gênero no principado romano, a partir das representações contidas nos epigramas de Marcial.

"Mestranda da UNESP/Assis. Contato: danimennitti@yahoo.com.br 
Ao pensar sobre essas sociedades do passado permite novamente voltar-se para o presente e refletir sobre essas questões. Segundo Feitosa,

refletir sobre povos que já viveram tem sentido porque oferece perspectivas para pensarmos a sociedade contemporânea e avaliarmos os interesses e as motivações que estimularam as pesquisas de outros momentos históricos (FEITOSA, 2008, p.124).

Esse passado, ou melhor, as representações desse passado, os usos feitos do mesmo são um instrumento de poder (FEITOSA, 2008, p.122). Ou seja, a escolha do objeto nunca é inocente e as reflexões feitas nessa análise e estudo do passado também não o são.

Segundo Pinto (2011, p.158), nas últimas duas décadas tem aumentado o número de trabalhos que estudam os homens e o masculino. Pinto diz que esses estudos são uma espécie de resposta aos estudos feministas que, visando dar maior visibilidade à mulher, dicotomizaram conceitos e nomenclaturas, ficando de lado debates e reflexões sobre o homem e o masculino. Foi muito usado e hoje ainda o é um pouco, a categoria homem como se essa fosse uma categoria universal. Conforme Pinto,

Não há nenhum padrão universal natural que conecte o conceito da palavra homem 'ao masculino'. Isto não quer dizer que não haja nenhum tipo de associação cultural ou que ela seja arbitrária. Porém, tais ligamentos são discursivos. Eles se fundamentam no contexto histórico particular e nos tropos linguísticos, para que as conexões sejam legitimadas e apresentadas como reais Da mesma forma, o masculino e o feminino se relacionam nas experiências vividas e pelos significados que os corpos recebem e produzem. Há ambiguidades e contradições constantes nas construções dos discursos que dão gênero aos seres humanos. De fato, uma maneira de melhor compreender como o masculino está sendo construído em uma determinada sociedade é começar por estabelecer como aqueles que se julgam masculinos definem suas próprias diferenças como um grupo (PINTO, 2010, p.159).

Masculinidade então não se refere necessariamente a homens e não se vincula necessariamente com o conceito de sexo e gênero como categorias bipolares e o discurso que quer difundir é de uma masculinidade dominante, hegemônica, que busca criar diferenças e hierarquizar o mundo a partir dessas regras (PINTO, 2011, p.159).

Admite-se então que não há apenas uma única forma de ser mulher e de ser homem, e sim múltiplas formas e maneiras de constituição do masculino e do feminino. A dominação masculina e a suposta "supremacia" do poder do "homem" sobre a "mulher" já não é mais capaz de responder satisfatoriamente sobre a diversidade de comportamentos e situações históricas (FEITOSA, 2008, p.125). Os estudos de gênero foram reconhecidos então, mas 
foram delegados a um setor diferenciado, separado, demonstrando assim como as relações de poder e, ainda mais, as relações de poder ligadas a questão de gênero encontram-se também presentes no próprio fazer historiográfico.

Analisar a questão da masculinidade, de gênero no passado exige também compreender essa experiência no presente. Evidencia-se desse modo a utilidade do gênero enquanto categoria analítica para a História, e mais especificamente, para o estudo da Antiguidade romana.

A masculinidade foi (e muitas vezes ainda o é) vista como algo dado, natural e, portanto, inquestionável, uma obrigação da qual ele não pode fugir. Nesse afã de manutenção dessa dominação masculina, dessa determinada ideia de homem, houve o empenho em afirmar e reafirmar essa ideia de masculino, masculinidade e virilidade.

Esses preceitos que constituem os elementos característicos do ser masculino, exigidos a esse homem, é, por assim dizer, um ideal, uma construção. A virilidade, além do fato de ser uma construção, ser constantemente cobrada e ter a necessidade de ser sempre reafirmada, é o princípio de uma grande vulnerabilidade (BOURDIEU, 1999, p.36).

\section{Marcial e os epigramas}

Marco Valério Marcial (Marcus Valerius Martialis) nasceu entre 38 e 41 d.C, em um povoado denominado de Bílbilis, situado na Hispânia terraconense (perto do que é hoje a atual Calatayud). Ele morreu na Hispânia, provavelmente em sua cidade de origem, entre os anos de 102 e 104 d.C. Até, aproximadamente, desde o ano de 64 até o ano de 98 viveu em Roma, e a maior parte de sua produção poética situa-se nesse período, com exceção dos livros XII, que será publicado em 101-102, momento em que regressa à sua terra natal. Sua condição de cliens dentro dessa sociedade fazia-o produzir seus trabalhos dentro dos pressupostos dessa aristocracia romana, mas ainda assim era possível a ele tecer críticas mordazes a certos costumes.

De acordo com Parra (2012), Marcial se tornou um grande expoente do gênero epigramático, sendo que sua obra possui cinco grandes características. A primeira delas é a brevidade, pois grandes obras seriam pouco estimulantes para o leitor (PARRA, 2012).O epigrama também devia ser alegre, em contraposição a seriedade da epopeia. Tanto Citroni quanto Parra (2010) diz não haver em Marcial uma intenção moralizante muito acentuada; não há nele uma indignatio, uma forte intenção moralizante nos epigramas dele como há nas sátiras de Juvenal. Ainda vale ressaltar que em Marcial a crítica não se destina a pessoas em 
particular, mas a tipos e que seus epigramas são em sua maioria satíricos, podendo ele também ser enquadrado no gênero literário da sátira.

De acordo com Parra (2012) ela diz que a sátira realiza uma apologia dos costumes ancestrais e ridiculariza atitudes e condutas que são divergentes do tradicional, ou seja, de algum modo há um papel moralizante, uma intenção moralizante. A sátira ainda possui três características básicas (2012): a sátira tem uma intenção moralizante; sua forma de expressão é o ridículo e a fonte psicológica é a indignatio, a indignação contra o desrespeito aos princípios morais, éticos, etc.

Uma das características marcantes de Marcial é o uso de uma linguagem, por assim dizer, obscena. Essa linguagem obscena torna-se então uma técnica argumentativa, no intuito de expor e ridicularizar, através do satírico, do cômico, um dado elemento social romano. Às vezes é mais incisivo, às vezes exageradamente cômico, provocando muitas vezes um resultado absurdo ou paradoxo. Nessa utilização de uma linguagem cômico-satírica, deixa entrever as contradições nos costumes e até mesmo uma contradição no que diz respeito às visões sobre a virilidade.

\section{O homem romano enquanto cidadão}

Cidadãos são todos aqueles nascidos livres, que podiam pagar impostos, que podiam ser convocados em caso de guerra e que poderiam efetuar uma participação nas decisões políticas; ou seja, no caso, só os homens adultos (NICOLET, 1992, p.22). Desse modo, sua participação na vida da cidade transforma-o, numa perspectiva geral, em um sujeito de direito. A cidadania é também um modo de vida. Cidadania é um conceito, uma concepção oriunda do conjunto dos cidadãos e para os romanos. Cidadania, cidade e Estado são uma coisa só e esta coletividade só existe se existirem cidadãos (FUNARI, 2003, p.72-73). Segundo Funari (2003, p.72-73), Ciuis é o ser humano livre e, por isso, ciuitas carrega a noção de liberdade em seu centro. Ao lado do direito de cidadania, situa-se a própria noção de liberdade, vista como a não submissão ou sujeição a outra pessoa (FUNARI, 2003, p.73).

Ganhar o estatuto de cidadão, em termos políticos e jurídicos, era objeto cobiçado, pois significava uma relevante maneira de ascender socialmente (FUNARI, 2003, p.73). Uma vez possuindo essa condição de cidadão, a mesma implicava em receber direitos e privilégio e também em cumprir deveres e obrigações.

De um modo ou outro, buscava-se uma imagem idealizada dessa época republicana. O principado romano "foi um mundo onde prevalecia a virtude cívica e militar" (NICOLET, 
1992, p.22); virtude cívica essa vivenciada mais fortemente, como na época da República, ou como um objeto já mais distante do contexto do principado, mas que ainda constava como um objetivo a ser alcançado, dentro do imaginário romano.

A manutenção da organização e a prosperidade nos rumos desta sociedade estavam vinculadas a conduta social desse cidadão (MENNITTI，2012a; MENNITTI，2012b; MENNITTI, 2012c; MENNITTI; ROSSI, 2012d). Construía-se uma moral que buscava dar as diretrizes a ser seguidas por este cidadão, a fim de que ele tivesse as devidas condições para o cumprimento de suas obrigações. Segundo Grimal,

Esta moral romana possui uma orientação nítida: o seu fim é a subordinação da pessoa a cidade e ainda há pouco tempo o seu ideal continuava a ser o mesmo a despeito de todas as transformações econômicas e sociais. Quando um romano, ainda no tempo do Império, fala de virtus [...] refere-se menos à conformidade com valores abstratos do que à afirmação em acto, voluntária, da qualidade viril por excelência, ao domínio de si - atribuindo, não sem desdém, à fraqueza feminina a impotentia sui, a incapacidade de dominar a natureza (GRIMAL,PP.67,1984)

\section{Moralidades e moral sexual romana}

Os romanos construíram uma imagem idealizada de si mesmos, dando destaque a um determinado modelo, ao qual procuravam se conformar e se encaixar, mesmo que este padrão estivesse presente apenas no âmbito discursivo. Este ideal tinha sua referência nos costumes, valores e princípios do passado, ou melhor, de seu passado republicano.

A moral, então, seria a responsável por enunciar os elementos necessários à manutenção da ordem em todos os seus domínios (ROBERT, 1995). O mos maiorum já não fazia mais parte desse mundo imperial, mas continuou servindo de parâmetro para aqueles que membros das elites romanas (GRIMAL, 1984).

Nos dizeres de Mennitti:

Este ideal romano expressava, além da questão do domínio de si, o domínio exercido na vida pública. Ser senhor de si e, mais ainda, ser viril, denotava não somente uma qualidade, mas uma virtude cívica. Era importante que este cidadão se comportasse de maneira viril, nos variados âmbitos de sua vida (MENNITTI, 2012a; MENNITTI, 2012b; MENNITTI, 2012c; MENNITTI, 2012 d). 
Para entender a moral sexual romana, um importante conceito é o conceito de puditicia e seu contraponto, a impudicitia, comumente traduzido como "virtude sexual". Ele não é o único termo relacionado à moral sexual; Ela é um conceito dotado de uma extensa polivalência, uma pluralidade muito grande de significados e aplicações, sendo um conceito específico dos romanos. A pudicitia faz parte de um modo muito próprio de pensar sobre o sexo e sobre ética (LANGLANDS, 2006, p.17).

A pudicitia organiza e direciona tanto a moral e a sexualidade individual quanto os relacionamentos com as outras pessoas e com toda a sociedade. Bem porque a moral e a ética são elementos a serem exibidos perante a sociedade. Pudicitia usualmente se trata da não participação em práticas sexuais proibidas, mas também se relaciona a outras ordens de virtudes.

Segundo Langlands (2006, p.17), a moral sexual pode propiciar uma rica chance de entender a relação entre o lado público da virtude na sociedade romana e o desenvolvimento ético do sujeito. Todavia, a moral sexual não é somente sobre penetração e os sujeitos da moral não são sempre homens fálicos; ela vai além da penetração, além do binômio atividade/passividade e além do desejo masculino de dominação.

A moralidade era princípio integrante da condição de cidadão, enquanto requisito e atributo necessário ao mesmo. O cidadão romano deve ser um uir bonus, ou seja, um homem iluminado, sensato, austero, dotado de qualidades que trabalham pelo bem da própria sociedade, cuja moralidade deve ser austera, solene, distinta. O homem romano:

Tinha uma função social e política de relevância. E para tanto, cabia a ele uma postura viril, adequada e correta para a sua condição. Isso era tanto mais exigido quando se tratava de um cidadão romano, um homem livre, $e$ ainda mais quando se tratava de um membro da elite romana (MENNITTI, 2012a; MENNITTI, 2012b; MENNITTI, 2012c; MENNITTI, 2012 d).

O estoicismo torna-se uma ferramenta que possui utilidade prática e também se constitui como uma fonte de progresso moral (LUZ; VENTURINI, 2007). O cidadão romano, bem como aqueles que obtiveram o título de cidadão em um momento posterior de sua vida, deviam se portar publicamente de maneira austera, devendo ser dotados de moderação, parcimônia, autocontrole, virtudes, enfim, possuidores de uma moral exemplar. Suas atitudes, na vida pública e privada, inclusive com relação aos prazeres deviam estar carregadas destes princípios morais, de virtude e seriedade.

Paul Veyne (2008, p.242) enxerga a existências de duas "morais" dentro da sociedade romana: uma seria uma moral mais austera, conservadora, com princípios bastante fechados; a 
outra seria uma moral mais liberal, mais aberta. É interessante nessa idéia de Veyne quanto a existência de outra moral, mais aberta, que faz oposição a moral dita oficial. Entretanto, não é interessante pensar em uma idéia tão binária de moral. Há uma diversidade de morais dentro da sociedade romana, e não apenas uma moral totalizante e outra que lhe opõe. Não se pode dizer que as concepções morais dos mais variados setores sociais romanos são as mesmas. Existe de fato um discurso que se pretende dominante e que busca sua legitimação. Contudo, isso não quer dizer que não haja discursos variados sobre a moralidade. Deve buscar-se fugir da idéia de uma moral "original" e de outra ou outras que lhe seriam derivadas.

As condutas morais, sociais e sexuais no período romano ocupam um lugar de destaque no seio da sociedade, sendo as mesmas fundamentadas em relações de poder, da cultura, enfim, dependentes de um conjunto de fatores (FOUCAULT, 2008, p.87-88). O modo como este sujeito se comportasse era poderia intervir (ou não) nos rumos dessa vida em sociedade e na vida do próprio indivíduo.

\section{A (des)construção do ideal de virilidade: masculinidades e questões sociais,culturais e de gênero}

A sexualidade, tendo uma considerável importância dentro desta sociedade, também devia ser vivenciada de modo que este cidadão deveria ter uma postura de dominação e controle, não importando se o parceiro sexual fosse do sexo oposto ou do mesmo sexo, desde que ele fosse o ativo. Ser passivo sexualmente, ainda mais se o parceiro fosse pertencente a uma condição social hierarquicamente inferior, era ser motivo de escárnio e reprovação. Ser viril, adotar uma postura "máscula" era igualmente importante, pois ser "efeminado" significaria demonstrar fraqueza.

Realizava-se a distinção "pelo fato de ser ativo ou passivo: ser ativo era ser um macho, qualquer que fosse o sexo do parceiro dito passivo. Ter prazer virilmente ou dá-lo servilmente é tudo a mesma coisa” (VEYNE, 2008, p.241). Em concordância com Mennitti “O homem, se tratando de um cidadão no sentido pleno, e ainda mais se este fosse um senador ou o próprio imperador, por exemplo, não podia ser visto efeminado" (MENNITTI, 2012a).

Para Sêneca,

A passividade é um crime para um homem que nasceu livre; é o dever mais absoluto de um escravo; para o alforriado, é uma complacência que tem o dever moral de ter para com o seu patrono (ROBERT, pág. 221, 1995).

A maioria dos trabalhos sobre masculinidade toma como fonte textos jurídicos, 
narrativas históricas, textos retóricos, textos literários e textos educacionais (WALTERS, 1997). Estas fontes são escritas por homens pertencentes às elites romanas, cujo público alvo a princípio são os próprios membros das elites e aqueles que possuem um status social um pouco mais elevado, que compartilham visões de mundo, possuem uma cultura em comum (WALTERS, 1997, p.34-35) e que fazem parte de uma linguística tradicional e uma educação retórica (WALTERS, 1997, p.34-35). Eram homens escrevendo para outros homens, o que restringe de certa forma o discurso enunciado. É um discurso que se propõe como dominante, hegemônico, difundido nas formas de discurso público (WALTERS, 1997, p.34-35).

A organização desta sociedade era responsabilidade do homem, sendo então necessário a ele deter uma posição viril, em consonância com sua imagem e papel de pater familias, dono de direitos majoritários sobre seus filhos e esposa e que exercia seu domínio e controle seu poder também nos problemas da cidade (VEYNE, 2008, p.240).

Além disso, a categoria social na qual se inseria o indivíduo também constava como parte do critério de classificação. Um cidadão romano tinha uma moral a ser respeitada e cumprida, devendo também manter a honra e manter limpo o "sangue romano" (ROBERT, 1995, p.220). Ele mantendo a conduta ativa, poderia realizar relações sexuais com outro homem, mas este deveria fazer parte de uma camada social inferior, como um escravo (VEYNE, 2008, p.242). Qualquer sentimento ou atitude que impulsione o cidadão a ser subjugado ou dominado, é vista como fraqueza, falha, como um atentado a virilidade.

Condizente com o dito por Mennitti

É marcante o ideal greco-romano de autodomínio, onde esse domínio significava além do domínio de si, mas o domínio dos outros e da cidade; este ideal de virilidade está ligado a vontade de exercer também poder sobre a vida pública (MENNITTI, 2012a).

A virilidade, significando uma soberania sobre si, é uma virtude do cidadão. Esse homem viril "era considerado um "soldado do dever cívico", um ser moralmente responsável" (MENNITTI, 2012a).

Esse homem romano tinha uma série de tarefas a realizar: o ofício da guerra, a escrever leis, a manutenção e preservação da gens. Ser, portanto, viril, era tido como útil para que o exercício dessas atividades, e por conta disso a carência de virilidade não era vista com bons olhos. A moral, por assim dizer, "oficial" tinha um aspecto mais austero. O mos maiorum, "moral cujo ponto de referência é a moral dos antepassados, essa moral rígida e bastante austera do passado republicano e mais fortemente agrário e rural, era ainda o referencial. Ser efeminado, não ser viril, era trair o mos maiorum" (MENNITTI, 2012a). 
Esses costumes ancestrais já não eram tão presentes no mundo romano, mas ainda assim era o referencial de comportamento dos membros da aristocracia romana.

Este ideal romano expressava, além da questão do domínio de si, o domínio exercido na vida pública. Ser senhor de si e, mais ainda, ser viril era uma qualidade muito desejada. Esta linha de pensamento tem uma profunda influência do ideal estoicista.

Através de mecanismos do cômico, do satírico, do humor, além de técnicas de argumentação, nas representações elaboradas por Marcial ficam evidentes as contradições existentes no cerne do fato. Ao expor e ridicularizar certos elementos mostra o paradoxo dessa miríade de condutas, fatos, ações, comportamentos. Não se limita a apenas servir de entretenimento e para fazer tão somente rir: quer mostrar a diversidade dessas experiências, realçando os paradoxos e contradições, ficando evidente assim que não há uma só visão, uma só conduta, uma só atitude, uma só moral: ela se expressa de maneira múltipla.

A moralidade expressa nas representações de Marcial não são tão duras e conservadoras quanto muitos dos escritores latinos, de um modo geral, como, por exemplo, Sêneca ou Juvenal. Ainda assim, há uma forte crítica aos mais variados elementos da sociedade Romana. Há de se lembrar, que ao analisar um discurso, deve se levar em conta quem, quando, onde, por que, para que, para quem escreveu, de onde escreveu. Sendo ele um cliens e vivendo no meio aristocrático, Marcial elabora críticas levando em conta os princípios dessa aristocracia; mas, ao mesmo tempo em que parece coadunar com os valores propostos por essa aristocracia romana, tece uma crítica a mesma, que se arroga detentora de uma série de valores e preceitos ditos corretos e austeros, mas que muitas vezes pratica aquilo mesmo a que critica e, ainda assim, essa crítica nem é sempre tão dura e moralizante, como em Juvenal, por exemplo.

A passividade era caracterizada como uma impudicitia, sendo considerada algo desprezível e vergonhoso. O impudicus, ou seja, aquela que adotava uma atitude passiva era motivo de reprovação e sujeito a ridicularização. Sob o risco de ser difamado, muitas vezes buscava-se camuflar, ou melhor, esconder a realização dessas práticas. É claro que isso não impedia que essas práticas acontecessem ou até mesmo que necessariamente elas se realizassem abertamente. Considera-se que o passivo dessa relação não possa ter prazer e que sua função se resume a dar prazer ao parceiro ativo; é $o$ ativo que merece gozar desse prazer.

Pode-se observar esse elemento no seguinte epigrama:

Teu jovem escravo tem dor no caralho 
Enquanto tu, Névolo, tens dor no cu.

Embora eu não seja adivinho, bem sei o que fazes.

(MARCIAL, Epigramas, III, 71)

Esse discurso dito oficial e dominante sobre a virilidade, sobre essa moral rígida e austera, sobre a questão da atividade/passividade é tão somente um dos discursos existentes; não é o único, nem o "mais verdadeiro". Mesmo entre os membros da elite, entre os cidadãos, não há uma unanimidade de discursos sobre moral, sexualidade, condutas. Segundo Cerqueira (2011), na Antiguidade existia uma espécie de normativa sexual, onde comportamentos eram definidos, recomendados e aceitos para o homem. Porém, nem tudo aquilo que é colocado como o aceitável, a norma, o que é "desejável e correto" constitui-se em uma regra, como a única via possível.

Segundo Foucault (1996, p.28), todo discurso tenta se firmar como foro de verdade, como se fosse a única verdade possível. Esse discurso sobre a moral, erotismo, sexualidade e conduta do cidadão, do homem da elite romana tem foram vistos por modelos interpretativos bastante normatizados e acabam tendo uma visão também normatizada sobre esse objeto.

No conjunto dos epigramas eróticos onde se fala da questão homoerótica, pode-se ver que, em sua esmagadora maioria, eles falam a respeito das relações pederásticas, da felação, de atos de efeminação, enfim, de condutas efeminadas e pederásticas, mas não diretamente da questão da virilidade. Por vezes, não se exalta direta e explicitamente a virilidade; ataca-se a pederastia e a efeminação. Esse rebaixamento da pederastia e efeminação possui um intuito: realizar um elogio da virilidade. Ele não retrata ou enuncia diretamente quais as atitudes adequadas para a adoção de uma conduta viril, mas o faz indiretamente, quando anuncia tudo aquilo que não deve ser feito, aquilo que é reprovável.

Segundo Mennitti,

Toda a construção discursiva epigramática ali representada estabelece uma atitude de exposição ao riso, de ridicularização das características desse sujeito e através dessa sátira, do escárnio, deixa entrever uma intenção: exaltar um ideal de comportamento, que é a qualidade viril por excelência (MENNITTI, 2012a).

As duas premissas básicas da masculinidade são o controle e a dominação. Segundo Williams (2010), no discurso sobre masculinidade podemos encontrar os termos imperium (dominação) e fortitudo (força), e os homens efeminados (assim como as mulheres) são caracterizados pela mollitia (suavidade, fraqueza). Pode-se atribuir outros termos aos efeminados. Segundo Williams (2010), pode ser listada a existência de termos como 
effeminatus (efeminado) ou muliebris (feminilizado), delicatus (delicado), enervis (enfraquecido, debilitado) e fractus (fraco, débil, subjugado). Outras práticas e hábitos, além do desejo de ser penetrado, podem ser constituidores da efeminação. Desde a depilação até o modo de flexionar a voz, o timbre, e também o modo de se vestir, o comprimento dos cabelos, andar de maneira delicada, falar de maneira feminina, exagerar nos perfumes, enrolar os cabelos, esses e outros pontos são colocados como características de efeminação. Ele não está apenas fazendo com que se pareça com um perfil de mulher, mas está gastando consigo mesmos cuidados excessivos com sua aparência, algo que é atribuído como um comportamento estereotipicamente feminino (WILLIAMS, 2010, p.156), o que dá a entender que esse homem deveria ser dotado de certa rusticidade na aparência, restringindo-se a cuidados limitados com seu corpo.

Isso pode ser visto em Marcial, no seguinte epigrama:

Você arrancou os pêlos do seu peito, perna e braços

E seu caralho tem os pelos cuidadosamente cortados.

Vocêfez tudo isso, Labienus, para sua amada - quem não o sabe?

Mas para quem, Labienus, você depilou seu cu?

(MARCIAL, II, ep.62).

Além dos atributos físicos, o ideal de virilidade engloba características de outras ordens também, como controle e dominação, sobre si mesmo e os outros. A virilidade / masculinidade dos homens romanos possuem dois conceitos básicos: virtus e imperium $\mathrm{A}$ virtus é uma qualidade onde está embutida questões e relações de gênero. Derivada de vir, etimologicamente significa masculinidade, virilidade, brio, coragem (WILLIAMS, 2010, p.106); virtus diz respeito a toda uma sorte de atributos morais admirados e desejados nos homens romanos. Sendo assim, para os efeminados não seriam possíveis essas qualidades. Virtus então, segundo Sêneca, seria o oposto dos vícios e/ou hábitos femininos (muliebra vitia) (WILLIAMS, 2010, p.106).

Virtus também pode ser relacionada com imperium, que significa o controle ou dominação que um magistrado exerce sobre o povo romano, que um general exerce sobre seu exército, que o homem exerce sobre as mulheres e escravos (WILLIAMS, 2010, p.106). Imperium também poderia ser usado com o significado de sobre as emoções (WILLIAMS, 2010, p.106). Emotividade, sensibilidade, languidez, fraqueza, fragilidade, suavidade, dentre outras sensações, sentimentos e emoções são considerados atributos femininos e, portanto, indesejáveis para um homem que se diz viril. Um homem propriamente viril deve controlar seus desejos e medos, sua dor, ser resistente, corajoso, perseverante, vigoroso e disciplinado. 
Mas por que a dominação é um fator tão importante no ideal de masculinidade / virilidade? Segundo Williams (2010, p.156), a masculinidade é um status conquistado; meninos devem ser construído homens, enquanto meninas apenas se tornam mulheres - muitos rituais e devem ser realizados para fazer o homem; ele pode falhar no seu intento a qualquer instante.

Em latim, quando um homem é penetrado por outro na relação sexual, usa-se a expressão muliebria pati, sendo ele definido como "tendo uma experiência feminina" (WALTERS, 1997, p.35-36). Ou seja, o que aconteceu a ele é o mesmo que aconteceu a uma mulher. Nesta expressão, uma das partes envolvidas na relação é vista como a parte sofredora, desprovida da possibilidade de prazer. Isto está de acordo com o discurso dito dominante e oficial de que o sexo é uma via de mão única, onde alguém impõe absolutamente seu poder, obtendo prazer egoisticamente, em detrimento da outra parte envolvida. O parceiro ativo é concebido como possuidor de um falo e no ato sexual necessariamente teria que haver penetração; o falo é visto então como um elemento essencial da relação sexual e somente o ativo e penetrador obtém prazer. É interessante quando Walter coloca que a categoria homem, a palavra homem, no sentido de um "ser humano homem", tem um uso restrito no latim (WALTERS, 1997, p.38). Aqueles homens que não atingiram a idade adulta não são chamados de viri; eles são chamados de pueri, adulescentes ou outros termos que demonstrem que este não chegou a idade adulta (WALTERS, 1997, p.38). Homens escravos e ex-escravos, quando adultos, não são chamados de viri, mas preferencialmente de homines, terminação também usada pela elite para designar os homens de condição social inferior (WALTERS, 1997, p.38). Vir não significa apenas um homem adulto, mas um homem romano que nasceu livre é cidadão e possui condição social elevada.

Entre um dado discurso dito oficial, entre o que constituía esse ideal viril do cidadão e como essas experiências se davam fora desse discurso, como elas ocorriam na "realidade", há um distanciamento.

O corpo, e no caso aqui estudado, o corpo do homem romano deve ser entendido como um corpo socialmente construído. Os atributos dos corpos e as relações sexuais ficam marcados por determinações de ordens variadas. Equivoca-se ao pensar sobre a significação da categoria de gênero e sexual como algo em si. O corpo, nas suas mais variadas ações, movimentos e deslocamentos são revestidos de significação social.

Dentro das representações elaboradas por Marcial nos epigramas, é possível encontrar um determinado contingente de epigramas que fazem referência a Priapo e os respectivos cultos feitos a ele. O deus Priapo é caracterizado por seu enorme e sempre ereto falo, sendo 
responsável pela proteção de campos e hortas. Diversas representações fálicas estavam presentes em diversos artefatos da cultura material.

O historiador Pedro Paulo Abreu Funari, estudioso, dentre outros temas, da sexualidade romana, cita também em seus estudos as significações da simbologia do falo, dizendo que o culto ao falo, o culto a Priapo, condiz com costumes apotropaicos, cujo objetivo é dar proteção e afastar o mau olhado (FUNARI, 2003, p.316).

Na concepção de Funari, o falo é um ícone da fertilidade. E ainda

O membro masculino em ereção era associado, na Antiguidade clássica à vida, à fecundidade e à sorte. A própria palavra falo, emprestada pelos romanos aos gregos, designava primordialmente, objetos religiosos em forma de pênis, usados no culto de Baco. (...) O falo não apenas afastava o mal como trazia sorte e felicidade. Recorde-se que a palavra latina felicitas, a um só tempo, "felicidade" e "sorte", ambos os sentidos derivados do sentido original de felix, "fértil”" (FUNARI, 2003, p.316).

A visão de que o falo "cresce", "se levanta" é uma traduz bem essa concepção do homem como agente fecundador, que dá a vida (BOURDIEU, 1999, p.20). A potência e o vigor sexual são alguns dos símbolos dessa virilidade, dessa capacidade de produzir e gerar a vida, símbolos de força, fertilidade e honra e da capacidade desse homem de dominar, explorar. Isso fica bem ilustrado no seguinte epigrama de Marcial:

Há algum tempo, Luperco, que o teu membro deixou de levantar-se,

Embora, com afinco, te esforces por o endireitar.

Mas de nada valem as eucas ou os bolbos afrodisíacos

E já nem a lasciva segurelha te aproveita.

Começaste a corromper, com teus bens, bocas inocentes:

E nem assim revive a solicitada Vênus.

De tal fenômeno, quem há que não fique admirado ou possa acreditar

Que o que se não mantém de pé se mantém caro, Luperco, para ti

O corpo deste homem romano é atravessado por discursos. Bourdieu esclarece "O mundo social constrói o corpo como realidade sexuada e como depositário de visão e de divisão sexualizante" (BOURDIEU, 1999, p.18).

A virilidade configura-se em uma espécie de ethos desse homem e cidadão romano, enquanto qualidade, atributo, virtude, dever e também constituinte da dignidade desse sujeito enquanto homem em si e enquanto cidadão e também está vinculada também com os caracteres e atributos físicos, que são comumente associadas ao gênero masculino.

Para Bourdieu 
A virilidade, em seu aspecto ético mesmo, isto é, enquanto quidade do uir,uirtus, questão de honra (nif), princípio da conservação e do aumento da honra, mantém-se indissociável, pelo menos tacitamente, da virilidade física, através, sobretudo, das provas de potência sexual (...) que são esperadas de um homem que seja realmente um homem. Compreende-se que o falo, sempre presente metaforicamente, mas muito raramente nomeado e nomeável, concentre todas as fantasias coletivas de potência fecundante (BOURDIEU, 1999, p.20).

Representações fálicas, seja nas formas de pinturas parietais, estátuas, entre outros lugares e objetos, era presença constante. Contudo, não havia essa conotação tão estritamente sexualizada, como há na atualidade. Por conotação sexualizada entenda-se uma conotação, compreendida posteriormente, ou melhor, na contemporaneidade, como um dado moralista, ligado ao pudor, que enxerga o falo apenas dentro do jogo de significado do ato sexual em si.

Aproximar certas ações humanas daquelas existentes no campo da natureza quase que confere uma objetividade a esse sistema. Os órgãos sexuais, construídos socialmente então, têm essa construção elaborada em um conjunto de escolhas orientadas, acentuando as diferenças ou apagando as semelhanças (BOURDIEU, 1999, p.21). O gênero masculino é, consequentemente, a diretriz dos princípios que governam essa sociedade

Bourdieu afirma que "o corpo tem sua frente, lugar da diferença sexual, e suas costas, sexualmente indiferenciadas e potencialmente femininas, ou seja, algo passivo, submisso" (BOURDIEU, 1999, p.26). A parte posterior do corpo seria então um lugar comum aos dois sexos, ligado de alguma forma ao feminino, algo passivo e, portanto, sujeito a uma posição de ser dominado nessa relação de poder.

O coito anal, tão presente no conjunto das representações (homo) eróticas de Marcial é tido como um fenômeno associado às relações homoeróticas masculinas. Não que não houvesse tal possibilidade de relação nas relações sexuais com o sexo oposto; mas era maiormente associada as relações sexuais entre os sujeitos do sexo masculino, como pode ser observado no seguinte epigrama:

[...] Uma só vez deixará que o ardente marido a enrabe, Ainda receosa dos primeiros golpes de um dardo novo.

A sua ama e a sua mãe proibirão que o faças mais vezes

E dirão: "Ela é a tua mulher, não o teu amante." [...] (MARCIAL, XI, 78)

As manifestações do ideal de virilidade encontram-se na lógica da coragem, da superação de obstáculos, dos grandes feitos, daquilo que pode ser considerado honroso, grandioso, um feito nobre. 
A questão de a relação sexual estar evidenciada como uma relação de dominação, de uma relação de poder entre os sujeitos ali presentes, reside no fato (além de outros) da existência dessa divisão binária entre o masculino, ativo, e o feminino, passivo e porque, na análise de Bourdieu (1999, p.27), este princípio cria, organiza, expressa, dirige o desejo - o desejo masculino como desejo de posse, como dominação erotizada, e o desejo feminino como desejo da dominação masculina, como subordinação erotizada, ou mesmo, em última instância, como reconhecimento erotizado da dominação (BOURDIEU, 1999, p.31).

Estabelecem-se normas de como deve se constituir esse homem, criando assim uma série de referenciais. Esses referenciais por sua vez determinam de que maneira o poder é distribuído, ou seja, de que maneira e quando um controle pode e/ou deve ser estabelecido ou quais são as possibilidades de acesso diferenciado aos recursos materiais e simbólicos (SCOTT, 1990, p.18). O gênero está inserido, embutido na própria concepção e construção do poder.

A categoria "homem" e os elementos como "masculinidade" e "virilidade" são, para usar os termos de Scott (1990, p.20), categorias vazias e transbordantes. Vazias porque não existe um significado, universal e último, válido para todos os setores sociais romanos, de todas as épocas. E transbordantes, pois, por mais que o ideal de homem viril, forte, dominador, ativo, pareça estar rígida e fixadamente construído, consolidado, ainda possui no interior delas concepções alternativas, negadas ou reprimidas,

Deixar-se penetrar ou realizar a felação significa simbolicamente abrir mão de seu poder, autoridade e controle, deixar-se submeter, subordinar. Fica entendido assim que a desonra para um homem consiste em aproximá-lo de uma condição feminina e/ou de um setor social inferior. A satirização, a exposição ao ridículo, através (ou não) do humor, acusando a falta de virilidade deste sujeito, é colocá-lo numa posição vergonhosa. É importante ressaltar que, a passividade era reprovada não somente por aproximar o homem e cidadão romano da condição da mulher, mas também por aproximá-la de um sujeito pertencente a um setor social inferior, como os escravos, por exemplo.

Porém, esse esquema binário da atividade/passividade e da oposição cidadão/ livre ou escravo se evidencia por demais normativos, não sendo capaz de mostrar a diversidade de possibilidades de comportamentos, condutas, desejos e práticas desses sujeitos, incluindo-se dos membros das elites, dos cidadãos. Claro o modelo de virilidade almejado pela sociedade romana, aqui representado nos epigramas de Marcial, era uma das possibilidades de experiência desse sujeito, mas de modo algum é a única. 
Nas representações apresentadas por Marcial, em um primeiro momento, o modelo de virilidade e pederastia aceito e também, pode-se dizer, idealizados, como já foi bastante dito aqui, é de que o homem, principalmente o cidadão e membro da elite devia ser viril, ativo, dominador e receptor do prazer de forma também viril, ou seja, ele é o penetrador, enquanto que aquele de condição social mais baixa, um cliens, um liberto, um escravo, enfim, devia ser o passivo, dominado e dar o prazer servilmente, sofrer a lei viril, não podendo ter prazer. Esta é uma das alternativas existentes. Mas possivelmente existiam também alternativas, como, por exemplo, aquela onde ao sujeito que se encontra na posição de dominado e passivo também possa ter prazer nessa relação e/ou o ativo e dominador poderia dar prazer; ou ainda que o cidadão/membro da elite possa ser o passivo, ter prazer nessa relação; ou ainda uma relação entre dois cidadãos, dentre outras possibilidades. A sociedade romana, bem como também a sociedade atual, é recheada de possibilidades, nuances, alternativas. Como já foi dito, nem todos se encaixavam no modelo e no ideal proposto, haviam outras alternativas de existência, de subjetividades.

As representações da sexualidade, do erotismo, do gênero, buscam afirmar quais os usos legítimos desses corpos. Nessa divisão binária, o que constitui um determinado gênero, suas características, não deve conter elementos que compõem o gênero oposto, como se não pudesse haver elementos constitutivos de um gênero no outro: eles seriam, então, excludentes. Dotar-se de atitudes e posturas de um gênero diferentes seria como abrir mão do seu.

Esses corpos, socialmente construídos, devem estar diferenciados do gênero oposto. A dominação masculina está "implícita nas rotinas da divisão do trabalho ou dos rituais coletivos e privados" (BOURDIEU, 1999, p.34). Uma série de mecanismos é utilizada para consolidar, legitimar e perpetuar essas relações de poder dentro das estruturas sociais.

O modo de se utilizar e se servir desses corpos, de se conduzir e comportar social e sexualmente são "a naturalização de uma ética" (BOURDIEU, 1999, p.16-20). A subjetividade presente nessas relações de podem tem também uma determinada objetividade.

Esta concepção institui o falo como símbolo de virilidade, honra e virtude bem como "as diferenças entre os corpos biológicos em fundamentos objetivos das diferenças entre os sexos" (BOURDIEU, 1999, p. 32-33).

O ideal de virilidade, a masculinidade do membro da elite e cidadão romano, que é então colocado como modelo de masculinidade dominante, tenta se instituir como concepção geral (e, diga-se de passagem, generalizante) de comportamento do homem romano e/ou 
ainda como diretriz normativa que visa disciplinar esses sujeitos e definindo relações assimétricas de gênero e sexualidade.

A construção de todos os mecanismos e ritos sociais que são enunciados como os princípios constituidores e organizadores desse ideal de virilidade inscrevem-se na subjetividade desses sujeitos como princípios da sua configuração enquanto um indivíduo do gênero masculino, de sua transformação em um verdadeiro homem. É um dever social, uma virtude cívica, uma qualidade necessária do cidadão, mas acaba por se tornar também numa virtude e dever para consigo mesmo, um ethos masculino, viril, para manutenção da sua honra e dignidade como homem. E essa relação de poder está inserida não só no âmbito das relações desse sujeito com as instituições, com a organização institucional, das mais variadas ordens, mas também no seio de suas relações interpessoais.

Walters argumenta que o protocolo sexual que define os homens como penetradores impenetráveis pode ser mais frequentemente visto no contexto de um modelo conceitual aristocrático, onde aqueles que possuem uma posição social mais elevada devem proteger seus corpos de todos os tipos de ataques (WALTERS, 1997, p.35).

Isto mostra como as categorias de gênero na sociedade e culturas romanas estão relacionadas também com a hierarquia social, com as condições sociais dos envolvidos nessas relações. Um homem que está posicionado em uma condição social mais baixa não é um homem no sentido pleno e, portanto a suposta impenetrabilidade de seu corpo é deficiente (WALTERS, 1997, p.35). O status social é um dos fatores principais da integridade corporal e da liberdade e, no caso de uma suposta carência, deficiência neste sentido, é um elemento que permite a invasão.

Homem no contexto romano não se refere simplesmente ao sexo biológico, mas faz parte de um status social e de gênero, e este último, por sua vez, envolve outros elementos de diferença social, como o fato de ter nascido livre ou não, se é cidadão ou não e a respeitabilidade de um modo geral (WALTERS, 1997, p.35).

Essas afirmações normativas que dizem respeito à masculinidade, virilidade, a efeminação, a atividade, a passividade, não são estabelecidas a partir do consenso social sobre o seu significado e função. Elas são construídas com base no conflito, no intenso jogo de forças discursivas, muitas vezes discordantes. A existência de um determinado discurso dito oficial, dominante, que tenta impor uma concepção a respeito da virilidade não exclui a existência de discursos que lhe façam oposição, que resistam. Um discurso que procura constantemente exaltar a virilidade do homem romano e condenar também a sua passividade 
não retira de campo a existência de outros discursos que divergem dele, que enxerguem outras possibilidades para essas relações e para a subjetividade desse homem.

O discurso da virilidade não foi elaborado em um bloco único, que persistiu e foi historicamente reconstruído dentro da sociedade romana. Ele foi um objeto constante de diferentes visões. Dentro do conjunto das representações epigramáticas de Marcial, fica bastante evidente essa correlação de forças; é possível perceber que, concomitante ao esforço em tentar legitimar a virilidade e os atributos a ela relacionados, vislumbra-se ideias mais maleáveis concernentes às atitudes, condutas e comportamentos desse homem e cidadão romano, sujeitos que encontram possibilidades diferenciadas para a sua constituição. Há quem se enquadre no ideal de cidadão viril, ativo, forte, dominador; e há quem não se enquadre nesse perfil desejado, que escape dessa normatividade. Não há um ideal fixo de como deve ser constituída a virilidade. Os homens romanos, os cidadãos romanos não encaixam permanentemente e/ou seguem a risca os requisitos e princípios da sociedade e do discurso (dito oficial) da moralidade; nem nas sociedades posteriores (incluindo a nossa sociedade contemporânea). Nos dizeres de Joan Scott "Além disso, os homens e mulheres reais não cumprem sempre, nem cumprem literalmente, os termos das prescrições de sua sociedade ou de nossas categoriais analíticas" (SCOTT, 1990, p.20).

A categoria "homem" e os elementos como "masculinidade" e "virilidade" são, para usar os termos de Scott (1990, p.20), categorias vazias e transbordantes. Vazias porque não existe um significado, universal e último, válido para todos os setores sociais romanos, de todas as épocas. E transbordantes, pois, por mais que o ideal de homem viril, forte, dominador, ativo, pareça estar rígida e fixamente construído, consolidado, ainda possui no interior delas concepções alternativas, negadas ou reprimidas,

Em um primeiro movimento, algumas representações epigramáticas de Marcial dão a entender que existe um discurso que busca construir uma identidade para esse homem e cidadão romano, como um homem bom (uir bonus), viril, forte, dominador, ativo, que controla. Essa identidade do homem e cidadão romano vem a calhar com as estruturas sociais e políticas, almejando atingir certos objetivos dentro dessa sociedade, dentro de necessidades e contextos contingenciais, ou melhor, necessidades e contextos específicos de cada momento histórico. Em um outro momento, esse tipo de identidade estabelecido pelas estruturas dialógicas consensuais podem não mais servir ao interesse da política. Isso denota, como diz Judith Butler "que as identidades podem ganhar vida e se dissolver, dependendo das práticas concretas que as constituam" (BUTLER, 2003, p.37). 


\section{Considerações finais}

Tendo em vista o exposto, é possível chegar-se tecer algumas considerações. Em primeiro lugar, é visível o quanto a virilidade, masculinidade, sexualidade, amor, erotismo foram apropriados pelos discursos modernos e contemporâneos, fazendo usos arbitrários deste passado, a fim de legitimar as relações de poder do presente.

$\mathrm{O}$ conceito de virilidade e masculinidade, assim como o significado da categoria homem e a moral sexual, apresentados nas representações contidas nas fontes são pertencentes as concepção de mundo elaboradas pelas elites romanas, onde o intuito é a construção de um discurso dito oficial, dominante e hegemônico, ligado a manutenção de certos valores e princípios. Uma visão idealizada do que é ser romano, ser cidadão, do que é a sociedade romana gera a necessidade de elaborar, difundir e manter certos discursos para manter certas estruturas culturais e sociais.

O ideal de virilidade está ligado aos conceitos do que é ser cidadão, do que é ser homem e o que é fazer parte de um status social elevado, cuja moral se pretende rígida e austera. Contudo, como foi dito, essas concepções dizem respeito a homens romanos da elite, não se aplicando aos homens das demais condições sociais, e mesmo dentre todo o contingente masculino da aristocracia romana. Outras variedades de fontes, como, por exemplo, as inscrições parietais de Pompéia, mais ligadas as camadas populares romanas, podem fornecer diferentes concepções, que podem divergir daquelas apresentadas pelas elites. Pode-se ainda buscar nas fontes literárias, como a que foi utilizada no presente projeto, maneiras diversas de leitura desses discursos. Há fontes que, mesmo ligadas as elites, podem apresentar um discurso diverso daquele que se apresenta como dominante. Não há uma só moral e sexualidade na sociedade.

É perceptível nas representações elaboradas por Marcial como a virilidade, a masculinidade, enfim, a sexualidade e as questões de gênero se relacionam com os demais segmentos da vida em sociedade, como a moral, as hierarquias sociais, a política, entre outros. Marcial se mostrou uma fonte bastante rica nesse sentido, pois suas representações abordam diversas modalidades de atividades, recheadas de nuances.

Ao mesmo tempo em que ele faz o jogo da elite, da qual em dependente, ele consegue encontrar espaço para a crítica social. Não há uma só moral e/ou sexualidade na sociedade romana, nem tampouco uma dupla moral: existem múltiplas e diferentes morais, assim como múltiplas e diferentes sexualidades. Dentro da sociedade romana é perceptível uma 
heterogeneidade de discursos, que fornecem muito mais complexidade a configuração e, consequentemente, ao entendimento da sociedade romana.

\section{Referências Bibliográficas}

BOURDIEU, Pierre. A dominação masculina. Trad.: Maria Helena Kuhner. Rio de Janeiro: Bertrand Brasil, 1999.

CERQUEIRA, Fábio Vergara. Sobre efeminação e virilidade: a Grécia vista do Pampa. MÉTIS: história \& cultura - v. 10, n. 20, p. 81-109, jul./dez. 2011

CHARTIER, Roger. A história cultural: entre práticas e representações.Trad.:Maria Manuela Galhardo. Lisboa: Disfel; Rio de Janeiro: Butrand Brasil, 1990.

CITRONI, Mario (Dir.).CITRONI,M.;CONSOLINO,F.E.;LABATE, M.;NARDUCCI (orgs.).Literatura de Roma Antiga. Co-autores da tradução: Margarida Miranda e Isaías Hipólito.Revisão da tradução:Walter de Sousa Medeiros. Lisboa: Fundação Calouste Gulbenkian, 2006.1286p.

DEZOTTI, José Dejalma. O epigrama latino e sua expressão vernácula. Dissertação de Mestrado. SãoPaulo, 1990.

ECO, Umberto. Interpretação e Superinterpretação. Tradução: Mônica Stahel. São Paulo: Martins Fontes, 2005. $184 \mathrm{p}$.

FEITOSA, Lourdes Conde. Homens e mulheres romanos: o corpo, o amor e a moral segundo a literatura amorosa do primeiro século d.C (Ovídio e Petrônio). Dissertação (Mestrado em História). Assis, SP: Universidade Estadual Paulista - Faculdade de Ciências e Letras, 1994.

FAPESP, 2005. 168 p. Amor e sexualidade: o masculino e o feminino nos grafites de Pompéia. São Paulo: Annablume . História, gênero, amor e sexualidade: olhares metodológicos. Revista do Museu de Arqueologia e Etnologia. São Paulo, 2003, n. 13. pp. 101-115.

Gênero e o erótico em Pompéia. In: FUNARI, Pedro Paulo Abreu; FEITOSA, Lourdes M. G. C.; SILVA, Glaydson José da. (Org.). Amor, desejo e poder desejo e poder na Antigüidade: relações de gênero e representações do feminino. Campinas, 2003, v. 1.

Gênero e sexualidade no mundo romano: a Antiguidade em nossos dias. História: Questões \& Debates, Curitiba, n. 48/49, p. 119-135, 2008. Editora UFPR

FEITOSA,Lourdes; GARRAFONI, Renata. Dignitas and Infamia: Rethinking marginalized masculinities in Early Principate.Stud.hist.,Hantig., 28, 2010, pp.57-73.

FOUCAULT, Michel. A mulher / os rapazes: História da sexualidade (extraído da História da sexualidade v.3). Tradução: Maria Theresa da Costa Albuquerque. Rio de Janeiro: Paz e Terra, 1997.

História da sexualidade I: a vontade de saber. Tradução Maria Thereza da Costa Albuquerque e João Augusto G. Albuquerque. 17 ed. Rio de Janeiro: Graal, 1988. 174 p. História da Sexualidade 2: o uso dos prazeres. Tradução: Maria Theresa da Costa

Albuquerque. Revisão técnica: José Augusto Guilhon Albuquerque. Rio de Janeiro: Edições Graal, $4^{\text {a ed., }} 1985$. $232 \mathrm{p}$.

História da Sexualidade 3: o cuidado de si. Tradução: Maria Theresa da Costa Albuquerque. Revisão técnica: José Augusto Guilhon Albuquerque. Rio de Janeiro: Edições Graal, $4^{\mathrm{a}}$ ed., 1985. . Microfísica do poder. Organização, revisão e introdução técnica: Roberto Machado. Rio de Janeiro:Graal,2008.295 p.

FUNARI, Pedro Paulo Abreu. Roma: vida pública e vida privada. São Paulo: Atual, 1993.

. Cultura popular na Antiguidade Clássica. São Paulo:Contexto,1989. 
.A cidadania entre os romanos. In: PINKSKY, Jaime; PINKSKY, Carla

Bassanezi. História da cidadania. São Paulo:Contexto,2003

"Falos e Relações Sexuais: Representações romanas para além da "natureza". In: FEITOSA, L., FUNARI, P. E SILVA, G. Amor, Desejo e Poder na Antigüidade. Campinas: Ed. Unicamp, 2003.

PINTO, Renato. Duas Rainhas, um Príncipe e um Eunuco: gênero, sexualidade e as ideologias do masculino e do feminino nos estudos sobre a Bretanha Romana. Tese (Doutorado em História) Campinas, SP: Universidade Estadual de Campinas, 2011.

FUNARI, Pedro Paulo Abreu, FEITOSA, Lourdes Conde e SILVA, Glaydson José da. Amor, desejo e poder na Antiguidade: relações de gênero e representações do feminino. Campinas, SP: Editora da Unicamp, 2003.

GIARDINA, Andrea (org.). O Homem Romano. Tradução: Maria Jorge Vilar Figueiredo. Lisboa: Presença, 1992.

GRIMAL, Pierre. A civilização romana. Lisboa: Edições 70, 1984.

GRIMAL, Pierre. O amor em Roma. Trad.: Hildegard Fernanda Feist. São Paulo: Martins Fontes, 1991.

KEITH, A.M. Sex and gender.In: HARRISON, Stephen (ed.). A Companion to Latin Literature.Ed.Blackwell Publishing, 2003.

KING, Helen. Preparando o terreno: sexologia grega e romana. Roy Porter e MikulásTeich (orgs.)In: Conhecimento sexual, ciência sexual. História das atitudes em relação à sexualidade. São Paulo:EDUNESP,1998.

LANGLANDS, Rebecca. Sexual Morality in Ancient Rome. Cambridge University Press, 2006.

MENNITTI, Danieli. O ideal de virilidade na obra de Marcial. Anais da ANPUH-SP, Campinas, $2012 \mathrm{a}$. Virilidade e pederastia nos epigramas de Marcial. XI Jornada de Estudos Antigos e Medievais - Programa de Pós-Graduação. Universidade Estadual de Maringá. 2012b. $O$ ideal de virilidade nos epigramas de Marcial. In: XXIV Congresso de Iniciação Científica, 2012, Assis. Publicação dos Trabalhos Apresentados, XXIV, 2012c. v. III.

MENNITTI, Danieli. ROSSI, A. L. D. O. C. . Virilidade e pederastia nos epigramas de Marcial. In: XI Jornada de Estudos Antigos e Medievais e IX Ciclo de Estudos Antigos e Medievais do Paraná e Santa Catarina, 2012, Maringá. Caderno de Resumos da XI Jornada de Estudos Antigos e Medievais e IX Ciclo de Estudos Antigos e Medievais do Paraná e Santa Catarina, 2012d.

LUZ, Camila Santiago; VENTURINI, Renata Lopes Biazotto. O pensamento estóico e sua importância para a formação do homem romano do século I d.C.VI Jornada de Estudos Antigos e Medievais - Trabalhos Completos.

NICOLET, Claude. $O$ cidadão e o político. In: O Homem Romano. Dir.: Andrea Giardina. Trad.: Maria Jorge Vilar de Figueiredo.Ed.Presença,1992.

OLIVEIRA, Andrea Lúcia Dorini de. Poder e mito: o principado na perspectiva da literatura latina: Tácito, Suetônio e Plínio, o Jovem. Assis: 1996. Dissertação (Mestrado em História).

PARATORE, Ettore. História da Literatura Latina. Trad.: Manuel Losa. Lisboa: Fundação Calouste Gulbekian, 1987.

PARRA, Amanda Giacon. A variedade de temas em Marcial e a possibilidade de análise das religiões estrangeiras. VIII Jornada de Estudos Antigos e Medievais e I Jornada Internacional de Estudos Antigos e Medievais. Os discursos acerca das religiões em Roma no Principado: diálogos entre Marcial e Juvenal. Anais do XXI Encontro Regional de História - ANPUH-SP, Campinas, setembro de 2012. . As religiões em Roma no principado: Petrônio e Marcial. Dissertação (mestrado em História). Assis, SP: Universidade Estadual Paulista - Faculdade de Ciências e Letras, 2010. $145 f$ 
PINKSKY, Jaime (Org.). História da Cidadania. São Paulo: Contexto, 2003.

POSSAMAI, P. C. Sexo e poder na Roma Antiga: o homoerotismo nas obras de Marcial e Juvenal. Bagoas: Revista de Estudos Gays, v. 4, p. 80-94, 2010.

ROBERT, Jean-Noël. Os prazeres em Roma. Tradução: Marina Appenzeller. São Paulo:Martins Fontes, 1995 (O Homem e a História).314 p.

SANFELICE, Pérola de Paula. Vênus e Marte: amor e sexualidade em conflito na história antiga. NEARCORevista Eletrônica de Antiguidade.

SCOTT, Joan. Gênero: Uma Categoria Útil para a Análise Histórica. Traduzido pela SOS: Corpo e Cidadania. Recife, 1990

VEYNE, Paul. Sexo e poder em Roma. Prefácio: Lucien Jerphagnon. Tradução: Marcos de Castro. Rio de Janeiro: Civilização Brasileira, 2008. 253 p.

(org.) O Império Romano. In: ARIÈS,F., DUBY,G. (Dir.). História da Vida Privada. Do Império Romano ao ano mil. Tradução: Hildegard Feist.V1.São Paulo; Cia das Letras, 1990.

WHITMARSH, Tim. Ancient History Through Ancient Literature.In:ERSKINE, Andrew. A Companion to Ancient History.Ed.:Blackwell Publishing Ltd, 2009.

WILLIAMS, Craig A. Roman Homosexuality. $2^{\text {nd }}$ edition. Oxford University Press, 2010.

WALTERS, Jonathan. Invading the Roman Body: Manliness and Impenetrability in Roman Thought. In:

HALLET, Judith P.; SKINNER, Marilyn B (editors). Roman Sexualities. Princeton University Press, 1997. 